\title{
Note from the Editor
}

This issue of EASTM starts with an article by Lisa Raphals comparing ancient Chinese and Greek modes of calculations and measurements and of building qualitative categories. By a precise investigation of ancient Greek geodesy and celestial measurements, as embodied in the works of Aristarchus, Archimedes, and Eratosthenes, and Chinese terrestrial and celestial measurements, described in such works as the Guanzi 管 子, the Classic of Mountains and Seas (Shanhai jing 山海 經), the Springs and Autumns of Master Lii (Lii Shi chunqiu 呂氏春 秋), the Huainanzi 淮南子, and the Gnomon of the Zhou [dynasty] (Zhoubi suanjing 淐骾算 經), Raphals comes to the conclusion that theories postulating a strict antinomy between quantities and qualitative categories is very problematic. Her criticism is that defining the Scientific Revolution as a clear-cut shift from categories to quantities formulates a polarity not borne out by Chinese and Greek microhistories. In her view, the understanding of complex interactions between cosmology, mathematics, observation, and analysis in ancient science is impeded by too simplistic an opposition between quantification and categorical thinking. One reason for arriving at this conclusion is that false assumptions can introduce inaccuracies into calculations that are based on quite accurate observational data and sound mathematical reasoning. Inaccuracies can also be evidence for genuine attempts at accurate measurement, as distinct from purely qualitative methods of analysis, or they result from genuinely inaccurate measurement or no measurement at all. In her substantial and highly informative article, Raphals points out a number of differences between Chinese and Greek styles of approach to calculation and measurements. For instance, she concludes that Chinese mathematicians may not have had an explicit concept of triangular plane figures, although they clearly identified parts of the triangle and knew how to use them in practical contexts. While Eratosthenes' calculation is based on the triangles' identical angles, the Chinese concept is grounded in an understanding of the proportionality of their line lengths. Greek mathematicians appear to have shown more interest in ratios and proportions than measurement, while the predominance of empiricism may have been overstressed in the Chinese case by some scholars. And in contrast to Archimedes and other Greek authors, Chinese writers did not proceed from axioms, but were concerned with the universality of their demonstrations. Raphals' article also contains a fine collection of metrological metaphors used in ancient China, which demonstrate the importance attached to measurements and imply an interesting tension between precision (in the crafts) and accuracy (in moral philosophy) during that period.

In issue 17 (2000) we published an obituary written by Hashimoto Keizō of the late Professor Yabuuti Kiyosi, who died on June 2, 2000. This was followed, in issue 18 (2001), by a collection of articles by Catherine Jami, Yano Michio, Qu Anjing, Tsukahara Togo, and Tōgo Toshihiro dedicated to this great Japanese historian of science. In this issue, we present two additional contributions about the life and work of Dr. Yabuuti. One article is the written version of a plenary speech on the Yabuuti paradigm in the history of Chinese science presented by 
Nakayama Shigeru中山茂 during the Ninth International Conference of the History of Science in China, City University of Hong Kong, on October 12, 2001. Nakayama Shigeru shows that, for various reasons, Joseph Needham's Science and Civilisation in China series did not pay due attention to Chinese calendrical science or mathematical astronomy, and thus to Yabuuti's work in this field. According to Nakayama Shigeru, the paradigm of Yabuuti's research style consisted in the use and combination of computational methods, historical surveys, and thorough studies of inter-civilizational contacts and exchanges. He also mentions some differences in the modes of approach and presentation between Yabuuti and Needham, the two giants of Chinese history of science and technology. There can be no doubt that the work initiated by Yabuuti Kiyosi will be continued by his students and friends, who can build on their teacher's achievements and now can make use of better tools, like computers, for their research into Chinese mathematical astronomy.

The second item dealing with the late Yabuuti Kiyosi in this issue is a comprehensive bibliography of the books, articles, reviews, introductions, translations, addresses, Festschriften and other items written by, or about, this great scholar in the years from 1932 to 2001 . This bibliography has been painstakingly

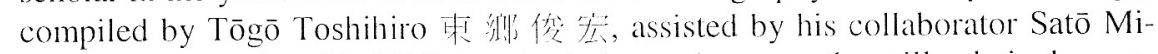
noru. We hope that this bibliography helps to improve the still relatively poor awareness of Professor Yabuuti's work outside of Japan, encouraging consultation of his studies both in the original language and in translation. This bibliography will also be published in electronic form on the EASTM homepage, and as such will be more easily searchable.

As usual, this volume contains a number of reviews, this time evaluating the content of some recently published books dealing with the history of Chinese metallurgy and mining, medicine, hydraulic engineering, as well as the transmission of western chemistry to China. In addition, this issue includes a review article on "New Directions in the History of Science in East Asia." In her collective review, Marta E. Hanson analyses three recently published compilations of articles on the history of science in East and Southeast Asia. By systematically discussing dimensions of the field's history, such as conceptual architecture, geographic representation, temporal emphases, comparative methodologies, and methodological innovations, Hanson concludes that these three volumes symbolize a watershed in the history of science, technology, and medicine in East Asia (and now even including Southeast Asia) over the past decade. In her view, they not only are an inspiring manifestation of an expansion of the geographic and temporal scope of the field in terms of participants and subjects, but also show a considerable refinement of contextual and comparative approaches. Moreover, they present methodological challenges to commonly held assumptions that should be of general interest to non-specialist as well as specialist readers.

We have to apologize that the scheme to publish two issues from the year 2002 onwards could not be realized. For a number of reasons we had to postpone this plan until 2003. This, consequently, will be also the year in which the special 
issue on traditional Vietnamese military technology with C. Michele Thompson as our guest editor will be published. It will include articles on Coa Loa, Thu'c Phan and the "magic" of early Vietnamese military technology (Marilynn Larew), "flaming tigers" and "burning dragons" or important elements of early modern Vietnamese military technology (George Dutton), the Vietnamese adaptation of foreign military technology (Nyuyen Thé Anh), and Vietnamese traditional medicine and its role in nationalism and in the organisation and development of the Viet Minh medical corps (C. Michele Thompson).

As ever, my thanks go to John Moffett and Jutta Rall-Niu for their invaluable editorial help, as well as to the contributors to this issue, the anonymous relerees, the Local Advisory Board, Editorial Committee and other members of the ISHEASTM for all their contributions, services, and critical advice. At the same time, I have to announce that Michael Schön, who will soon linish his PhD, recently left Tübingen and thus EASTM and moved to Taiwan to begin a new period in his life. We wish him all the best for his future career, and would like to express our deep and sincere gratitude for all his highly efficient and dedicated service as managing and production editor for the journal during the past four years. It is on the sound basis of his work that He Heng 何 $\mathrm{I}^{\mathrm{O}}$, a young Chinese from Yibin in Sichuan presently studying ethnology and Chinese studies at Tübingen University, was able to take over the post as managing and production editor so smoothly. There is no doubt that she will act with the same degree of dedication to the journal and will help us to realise all our plans for the issues to come.

Hans Ulrich Vogel

Seminar für Sinologie and Koreanistik

Eberhard Karls Universität Tübingen 